\section{Tokyo gears up for calamity}

\section{Tokyo}

THE Tokyo metropolitan government is spending hundreds of millions of dollars on the latest technology designed to manage disaster relief operations if Tokyo is hit by a major earthquake or typhoon.

The metropolitan government moved last month from old buildings in the centre of Tokyo to a new 48-storey skyscraper in the northwest of the city. The building Tokyo's tallest - cost $¥ 144,000$ million (more than $\$ 1,000$ million) and bristles with high-technology surveillance equipment that will gather information and direct rescue activities in the event of a disaster.

Tokyo lies on the edge of three colliding plates - the Pacific, Eurasian and Philippine Sea plates - and a major earthquake could hit the city at any time. In 1923, the Great Kanto Earthquake struck Tokyo, killing 140,000 people, and although a repeat is not thought to be imminent, several experts do think that such an earthquake could strike in the first few decades of the next century. Tokyo also lies in the path of typhoons that batter Japan in autumn and sometimes cause serious flooding in low-lying areas of the city.

Thus disaster prevention is serious business for Tokyo, and the equipment in the new building is correspondingly state-ofthe-art. On the roof are two panoramic television cameras on the east and west sides that can each scan through 180 degrees, giving a complete 360 -degree coverage of the city. The cameras have lenses that on a clear day allow government officials to zoom in on buildings in Tachikawa city, $30 \mathrm{~km}$ away.

The aim is to pinpoint fires that will break out all over the city if a major earthquake strikes. In the 1923 earthquake, it was fire storms that caused most of the 140,000 deaths.

In addition to those on the roof, special television cameras mounted on two helicopters operated by the Tokyo Fire Department and the Tokyo Metropolitan Police Department will be sent into the air to scan the city when disaster strikes. The cameras, mounted on arms off the side of the helicopters, are designed to remain level no matter how the helicopter rocks and they automatically orientate themselves so that north will

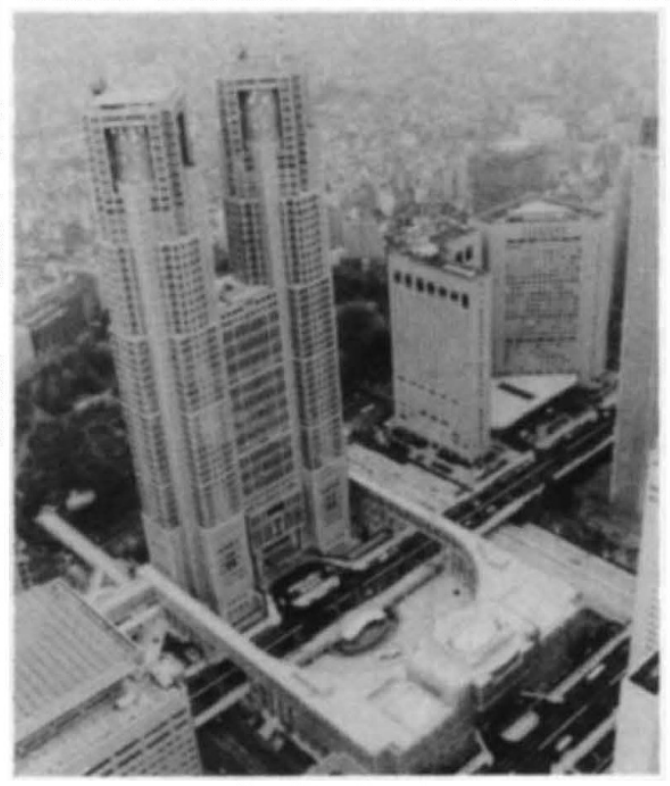

Awaiting disaster

always be towards the top of the television picture. They can also take infrared pictures at night.

At that point, the most important (and expensive) part of the disaster prevention system comes into play. The top half dozen floors of the city headquarters bristle with microwave radio antennas pointed at 23 local ward offices around the city as well as at national government ministries, police and ing. fire departments, headquarters of the selfdefence forces, television stations, telephone, electricity, gas and water utility companies. All in all, more than a hundred organizations in Tokyo are linked to the microwave radio communication system which can operate when ordinary telephone lines are broken by an earthquake or flood-

This communication system, which cost about $¥ 20,000$ million ( $\$ 150$ million), will be used to direct relief and evacuation operations and to gather the latest data on the state of the disaster from around the city.

Operations will be directed by the governor of Tokyo and other officials who will man the disaster prevention headquarters located between the eighth and ninth floors. Three huge screens on the wall of the headquarters will display live pictures from the television cameras and maps of the city showing the latest statistics on the spread of fires (or floods) and deaths in the city. Orders will be issued through a nearby communications room equipped with telephones and facsimile machines connected to the microwave communication system.

All of this preparation, however, will do little for the people who live and work in the areas around Tokyo. And if a major earthquake or flooding caused by a typhoon hits that city, it is almost certain to affect areas beyond the city limits. For example, the area of the Izu Peninsula, $100 \mathrm{~km}$ south of Tokyo, is one likely location for the epicentre of a major earthquake to hit Tokyo.

In such circumstances, coordination of disaster relief operations becomes the responsibility of the national government, which has not coordinated its disaster response as well as the city of Tokyo. Almost every national government ministry or agency has a section dealing with natural disasters, but there is no central organization in charge of them all. And expert observers express scepticism about the ability of all the various government ministries and agencies to act quickly and effectively in the event of a disaster.

For example, Peter Hadfield, a geologist, points out that when a Japan Airlines jumbo jet crashed into a mountain north of Tokyo early one evening in August 1985, it took hours for the Transport Ministry, which is in charge of the airline industry, to issue a request for help from the self-defence forces, which are under the jurisdiction of the Defense Agency. And no government response was given to offers of help from US Air Force bases in the outskirts of Tokyo that have helicopters equipped with night-viewing cameras. Rescue teams in helicopters were not despatched to the crash scene until early the next morning, by which time most of the survivors of the crash had died. 